\title{
"Trust" and "confidence" as socio-technical problems in the transformation of energy systems
}

\author{
Christian Büscher ${ }^{*}$ and Patrick Sumpf
}

\begin{abstract}
Background: For the development of a sustainable energy system, the public's contribution to the sustainment of the system's current operations will become vital. The public's role is expected to change from that of passive service abiders to active service providers, as anticipated by visions of prosumers, smart grids, demand side management, virtual power plants, and electric vehicle management. Smart technology and new business models will increase system complexity and the experience of uncertainty and risk for all parties. Actionability of the public's participation in the opportunities arising from the transformation of energy systems will become a problem.

Methods: With a qualitative functionalist method, we analyze the prerequisites of the public's participation: the capacity of social mechanisms, such as trust, for the solution of social problems. Functional problems affect the continuation of communication, i.e., the possibility of the sustainment of social reality. We isolate three case studies that illustrate concrete effects of trust, distrust, and confidence on three parties, respectively: consumers, investors, and those affected by grid extensions.

Results and conclusions: We argue that the social mechanisms of trust and confidence are more vital for consumers, investors, and those affected than previous research has noticed. These mechanisms determine the achievement of sustainability in energy systems by sustaining actionability as a favorable expectation (trust, confidence), or an unfavorable expectation (lack of trust, distrust). Even lack of trust and distrust can be valuable contributors on the road to sustainability, since they uncover flaws and setbacks of a fledgling smart grid.
\end{abstract}

Keywords: Smart grid, Complexity, Acceptance, Uncertainty, Risk, Prosumer, Consumers, Investors, Those affected, Decision-making

\section{Background}

The transformation of energy systems (ES) into smart grids-particularly in the domain of electricity-is not only a matter of technological proficiency. In fact, the far-reaching objectives and visions of systemic transformation require major qualitative changes in the relationship between the public and the ES [1-3]. "Smart" technologies and behavior, like smart grids, smart markets, or demand side management (DSM), are supposed to support the implementation of multiple alternative energy sources, in order to increase efficiency and sustainability of the provision, distribution, and consumption of energy. ${ }^{1}$ From

\footnotetext{
* Correspondence: buescher@kit.edu

Karlsruhe Institute of Technology (KIT), Institute for Technology Assessment and Systems Analysis (ITAS), Karlstr. 11, Karlsruhe 76133, Germany
}

the systems perspective, the potential of technological developments cannot be exploited without the public's active participation: "Consumers represent a cornerstone in the fulfillment of goals such as energy efficiency and savings, by their active participation through their actual utilization of the system" [4].

Proponents of smart grids assume that the public will adapt to the new technological reality once the opportunities become clear. Scientists, politicians, and economists call on the ability of potential users to rationally calculate risks and chances. ${ }^{2}$ To expose, analyze, and assess the consequences of these underlying premises is the motivation of our investigation. They rest on nothing less than the broad-scale modification of public attitudes toward the following: 
- New technical devices which are "intelligent, self-healing, autonomous machines" [5-7], into whose operation the majority of the public has no insight [8]

- Opaque markets in which rules of fairness cannot be enforced for certain, as it is unclear "who reaps the benefits, who bears the risks and burdens" [9]

- The complex of public administration and governmental agencies, which supervise the development of smart infrastructures, and on which the public has to rely [10-12]

The implementation of these changes will not be straightforward. In general, social scientists assume that the major obstacle for the implementation of a new technology is social acceptance. In the last decade, we have seen extended research on the matter of acceptance and energy system transformation: general assessments of regional situations like the USA [9]; the differentiation of dimensions of acceptance (socio-political, community, or market [13] dimensions); acceptance of institutional frameworks like socio-economic conditions or the consequences of innovation [14]; investigations of criteria determining acceptance (including criteria like community ownership [15], participatory exercises [16], perceived justice in planning procedures [17], values associated with large technical systems [18]); and many case studies on wind energy in general and offshore wind, smart grids, transmission lines, etc. However, this branch of research-just like most research on socio-technical systems-investigates causes for the achievement or non-achievement of positively valued developments and outputs (like public support for new technologies in particular and the ES transformation in general [19]); it investigates goal attainment following specific quotas of renewable energy or improvements to the ES concerning greater customer orientation or more sustainable, ethical, and effective developments [20]. In this sense, lack of acceptance is conceptualized mainly as a deficit that has to be overcome through educating the public, and it is assumed that once education is achieved, the related problems will probably vanish.

Contrary to the belief in promoting the public's understanding of science, everyday social life needs a "reduction of complexity" [21] to get things done; it needs "voluntary blindness." A "large measure of trust is necessary if we are to cooperate, manage the uncertainties and confront the risks of working towards a sustainable energy future" [22]. In truth, acceptance does not necessarily lead to the active involvement of persons; it may just result in passive tolerance.

As an alternative to deficit models (lack of acceptance or trust) and factor theories (causes for acceptance or trust), we introduce the application of functionalist methods [23] to the specific case of smart grid technologies for future energy provision. We are searching for the social conditions which render unlikely commitments likely. This search does not imply any evaluation of the outcome of such commitments. Rather, the application of this method should provide a deeper understanding of the underlying problem-free of preconception-before discussing policy options.

The alternative concept to acceptance is that of the relation of trust and confidence. Trust is a mechanism of complexity reduction, because it enables action in spite of uncertainty about the future [21, 24-26]. As a consequence, trust helps execute actions that would otherwise not have been effective [21], and it builds a foundation for the implementation of action potential [27]. Confidence is a behavior which is complementary to trust, and it is directed at abstract entities like infrastructures, politics in general, or markets. Given the need to reduce complexity and to absorb uncertainty, we assume that trust in systems and their respective decision programs, as well as confidence in the overall transformation of the systems, are necessary preconditions for actionability. ${ }^{3}$

Moreover, we argue that trust and confidence are interdependent. They systematically reinforce one another, and only if a certain threshold of trust and confidence is reached will people commit themselves to actively participate in the transformation process. Lack of trust may enforce a passive behavior; distrust may enforce autonomy, or the search for alternatives. These patterns are visible in energy-related roles such as consumers, investors, and those affected by grid extension.

Trust and confidence address specific functional problems which arise in socio-technical constellations like the ES. The task of this paper is to investigate what sociotechnical problems can be identified ("Socio-technical problems" section) and how social mechanisms like trust and confidence contribute to their solutions-without claiming that those solutions are genuinely positive for the overall development of future energy provision or society as a whole. We have to bear in mind that overconfidence and blind trust may be as damaging as the lack of trust.

\section{Methods}

Accordingly, this paper will present a sociological discussion on social mechanisms to cope with the increasing degree of complexity resulting from the ES transformation. For this purpose, theoretical arguments from sociological approaches, addressing functional problems of control, change, and actionability, will be combined with empirical insights. The empirical data has been extracted from 90 to $120 \mathrm{~min}$, semi-standardized interviews conducted with eight leading experts from various branches of the German energy sector. They include major technology companies, transmission service operators, federal and local business associations, and consumer and environmental 
associations. ${ }^{4}$ The narratives of these experts, combined with extensive document reviews, provide the main source for our descriptions of the German ES visions. Moreover, they guided our research toward the inclusion of complexity and the resulting challenges in the three case studies. All in all-referring to the functionalist method-we follow one of the leading methodical guidelines of technology assessment: to expose the premises of prospective technology programs, to analyze their secondary problems, and to bring all societal consequences to full display.

For a more thorough understanding of the societal dimension of ES transformation, we will expose structural, institutional, and operational problems ("Socio-technical problems" section). We will discuss how, on the operational level, problems of acting and decision-making under uncertainty have their roots in trust, lack of trust, or distrust. To illustrate the plausibility of our theoretical arguments and to illustrate concrete challenges, we explore trust issues in the German energy sector ("Trust and distrust as drivers of stability and change in ES transformation" section). Three case studies will be laid out, with consideration of the different situations which the public finds itself in, already, and more so in the future: consumers, investors, and those affected ("Results: three case studies about smart grids-consumers, investors, and those affected" section). Finally, we will discuss briefly how the existing "architecture of trust" may be modified and what consequences this can have on the development toward sustainability ("Discussion: an "architecture of trust" for ES" section).

\section{Socio-technical problems}

The ES interrelates technical and social processes to solve specific problems, in order to provide expected outputs. Prevailing research on socio-technical systems emphasizes either structural aspects or institutional aspects. While these aspects are crucial, we will also draw attention to operational aspects, thereby dealing with problems of action and decision-making. Since every socio-technical system poses a "linked series of sociotechnical problems" [28], we propose that socio-technical systems are expectation complexes of services (institutional aspect), to which technical and social systems contribute (structural aspect), to solve from moment-to-moment socio-technical problems (operational aspect). We will discuss structural and institutional changes which lead to complexity. Complexity results in the anticipation of contingency, which itself results in decision-uncertainty and risk. Problems of actionability concern-mainly but not exclusively-the operational dimension. In the following, we discuss socio-technical problems and why trust and confidence are requisite social mechanisms for the development of future smart energy infrastructures.

\section{Structure and control}

Previous research on the emergence of socio-technical systems $[29,30]$, on the governance of large technical systems $[31,32]$, or on socio-technical infrastructure systems $[28,33,34]$ analyzes the emergent qualities of entities wherein social and technical elements interrelate. It conceives of socio-technical systems as open systems or networks of heterogeneous elements, held together by a purpose: that of providing energy, transportation, water, or worldwide data exchange. It assumes that technical operations and social actions are functionally complementary $[35,36]$, and it focuses on antagonistic developments, stress, or breaches. Usually, one finds exogenous (environmental) or endogenous (systematic) factors triggering changes of the system's characteristics, which then influence the quality of the infrastructure service [37]. This makes future states or behavior of systems harder to predict (indeterminateness).

Concepts of socio-technical systems highlight the multiple, varying relations between heterogeneous elements, indicating a high level of "organized complexity" [38]. For the German ES Transformation, complexity is allembracing: Different types of power plants (for conventional and renewable energy sources) are connected to the network with transmission lines, distribution grids, and smart devices which contribute to the service of the ES. Moreover, different actors of the ES (administrative bodies, companies, communities, groups, and private persons) are interrelated through rules, contracts and markets, and regulations [33]. Control of such interwoven networks becomes vital.

Experts already face multiple challenges due to the changing structure of infrastructure systems; they are particularly challenged by the "complexity of these systems and the related emergent behaviors which may arise in collective ways, difficult to predict from the superposition of the behavior of the individual elements of the system" [39]. Given that the visionaries of smart grids propose even more integration of Information and Communications Technology (ICT), the problem of non-knowledge about the behavior of smart grids may progressively become the most significant issue for all involved, for operators, supervisors, investors, "prosumers", and citizens [40].

\section{Institutions and change}

Several concepts concerned with socio-technical systems accord an important role to institutions [41] and to processes of institutionalization [36, 42]. Recently, transition research has invoked the structural and institutional features of socio-technical systems with crucial infrastructure (such as energy, water, railroads, and telecommunications). A very prominent feature of transition research is the analysis of the relations of stability (configuration, structure, 
and institution) and of change (co-evolution, structuration, and institutionalization). Within the framework of transition research, the multi-level perspective addresses sociotechnical transition as a function of stability and change caused on three analytically distinct levels: regime, niche, and landscape. The regime is the dominant structure within a socio-technical system. In a regime, a multitude of actors and organizations is tightly interwoven into a network of mutual dependencies held together through formal and informal relations, e.g., through contracts and trust (respectively). The regime determines social relations by virtue of institutionalized expectations, such as cognitive rules of scientific observation, agreed upon knowledge, established technical paradigms, and belief systems $[35,36]$. In abstract terms, institutions entail that not every event, action, or decision is similarly possible, legitimate, or probable. Structures and institutions are necessary features of social life to provide orientation and to enable action.

The energy infrastructure in Germany is a highly regulated complex, with strongly institutionalized networks of incumbent actors, but it is now in flux because of the German ES Transformation. This transformation is executed as a real-time experiment of a socio-technical nature, comprising experiments with technical and social aspects (e.g., regulations or consumer behavior). "Research on energy has increasingly turned society into a laboratory - one in which the energy user and non-scientist can potentially play an active part in the experiment" [40]. To control such a transformation, a balance between tight experiment-reality couplings (which enables innovative, realistic, close-to-the-market benefits) and loose couplings (which disturb the system's operation as little as possible) is required. To foster social change, one needs to sustain action orientation with stable generalized expectations, while increasing learning capacities with less "resilient" institutions [43]. Nonetheless, due to the inevitable non-knowledge about the success of the German ES Transformation, the public may be opposed to a learning experience, and such opposition will, presumably, prevent their active involvement [40].

\section{Operation and intransparency}

The problems of control and change affect the operational dimension of the ES. Social operations include acting and decision-making. In socio-technical systems, operations are conditioned by technical determinism (1) and social dynamics (2). These are very distinct modi operandi.

1. In this paper, we refer to a technical operation on a physical, chemical, or biological basis, as a "functioning simplification in the medium of causality" [44]. In the sense of causal determination of technical operations, technology exonerates from contingency-if it works.
One does not need to know how technical devices operate, but with some experience, one can expect a certain output on a regular basis. This idea can be illustrated with the expression "trivial machine," coined by Heinz von Foerster [45]. Trivial machines are those machines which use $a$ set of rules in order to transform certain facts into other facts (for example, heat from combustion of coal boils water in a boiler to produce steam, which expands across a number of blades in a turbine, leading to rotation and, subsequently, to the generation of electricity). "Non-trivial machines," on the contrary, change the rules on how certain facts are transformed into other facts of their own accord. ${ }^{5}$ Therefore, we understand technology in connection with regularity of behavior; provided a machine functions, it will operate in accordance with the actors' stable expectations of what will happen when the machines operates. ${ }^{6}$

2. We refer to a social operation as communication (the basic operational element of social systems) based on meaning. Unlike technical operations, social operations entail the possibility of surprise. Successful communication is, first and foremost, unlikely. The synthesis of a threefold selection of information, utterance, and understanding constitutes communication. Selectivity implies the potential to surprise in every situation anew: People are always free to say "yes" or "no" to any kind of communication offer. Paradigmatically, this problem has been addressed by concepts emphasizing that social interaction is a precarious affair because of the freedom other actors possess. The social condition for collective actions, i.e., cooperative behavior (as pointed out by rational choice theory), is one important concept here [46]; the "problem of double contingency" is another [47].

From a functional perspective, sociological theory seeks to explain why all the occurrences we take for granted, because we observe them on a regular basis, are happening despite their indeterminateness (contingency, uncertainty, risk). Unlike technical operations and routinized, quasiautomatic action, social realities emerge when actors relate to each other via communication and when the threefold selection of information, utterance, and understanding creates meaningful distinctions which link communication to an identifiable unit (a social system) distinct from all other events (in the system's environment). "Such a model allows for a complex interplay of what information is being transferred, how it is transferred (whether intended or not), and then how it is received (which itself reinstitutes the communicative process by re-conceptualizing information)" [48]. Social realities have to solve problems of contingency, 
e.g., the surprise of unexpected events, so that structures and institutions can emerge and sustain themselves. Norms, rules, routines, values, etc., are contingent in their origins, but once they are established, they offer stable expectations. However, communication, as the basic element of social systems, always inherits the moment of surprise. Every social situation is comprised of events which bring about a new combination of determinacy and indeterminacy [47] - which is (or should) not be the case for technology - where only determinacy is in order.

\section{Structural coupling of technology and communication}

Since there is a sharp distinction between technical operations and social operations, the interrelations of the socio-technical should not be approached in terms of functional equivalency (like in the metaphor of the "seamless web") but in terms of structural coupling. A structural coupling implies that while technology is a topic of (or stimulates) communication, it does not determine, overlay, or substitute communication, because the type of operation is distinct: "The technical network of energy flow is completely neutral to communication; in other words, information is produced outside the network [...]. Causal relations between technological physics and communicated information are freed of overlap and take the form of structural coupling" [49].

The case of ICT illustrates this structural coupling clearly, for in spite of tremendous developments (speed, volume, and accessibility) in electronic data processing, social actors remain dependent on interpretation and choice in order to exploit the technological capacities. The information value of electronic data processing is determined by the processing of meaning by psychic or social systems. Actors are confronted with an enormous asymmetry between the visible, symbolic tokens on the interface of a system and the machines lying hidden behind the interface. Behind it are these programmed and trivial, but very complicated, machines which execute algorithms that greatly exceed the data processing capacities of human cognition. "Although they [computers] are manufactured and programmed machines, such computers function intransparently for consciousness and communication through structural couplings. Strictly speaking they are invisible machines" [49]. The structural coupling of technical and social realities produces both relief and new forms of stress. Unless uncertainty is absorbed by social mechanisms like trust and confidence, actionability cannot be sustained (Table 1).

\section{Trust and distrust as drivers of stability and change in ES transformation}

In the operational dimension of socio-technical systems, trust is a prototypical problem concerned largely with time. Similarly, in Simmel's "philosophy of money," trust implies a "quasi-religious faith" which is required to cope with non-knowledge of the future [50, 51]. Trust empowers persons to "act as if the future was certain" [21]. Recent research on "process views of trusting" [52] highlights the temporal dimension of trust. Trust and time are long-standing relatives. When building stable expectations of future developments, people have to commit themselves to a "leap of faith" [51], and this leap has become a focal point for research on trust.

According to Lewis and Weigert ([53], p. 25), the most "forceful" theoretical advances on conceptualizing trust in the past decades have been conducted by Möllering $[26,51,54]$. Möllering refers to Simmel's leap as the act of "suspending irreducible social vulnerability and uncertainty as if they were favourably resolved" ([54], p. 356). This theory on the act of "suspension," which is largely shared in the international research community, tries to account for the irrationality of trust that upholds favorable expectations even in the face of possible disappointment-the perception of risk [55]. In particular, this interdisciplinary approach attempts to conceptualize trust in a more holistic fashion than single disciplines-such as economics. It identifies the core of the trust problem in the irreducibility of uncertainty (as quoted above). This corresponds to the functionalist view of upholding actionability through trusting.

Comparing his own approach with game theory models of trust and comparable rational choice concepts, Möllering ([54], p. 356) explains that "The need to find alternative explanations is evident, because rationalistic explanations regularly face the paradox that they are either explaining trust away or explaining everything but trust." In this way, rational choice models of trust usually refer to measurability, or certainty, or cost versus benefit analyses. Yet these aspects are only one part of what trust is concerned with; they are merely concerned with reason ([54], p. 357). As a result of this limited view, game theorists who are

Table 1 Three dimensions of socio-technical problems

\begin{tabular}{llll}
\hline Dimension & Socio-technical problems & & Solutions \\
\cline { 2 - 3 } & Stability & Change & Governance \\
\hline Structure & Control of system performance, security & Complexity & Experiments, learning \\
Institution & General orientation, reliable outputs & Surprise & Confidence, trust \\
Operation & Actionability, participation & Intransparency & . \\
\hline
\end{tabular}


concerned with trust suffer from the assumption that it is knowledge or complete information that arouses trust or distrust. Möllering, on the contrary, alludes to the role of non-knowledge-absorbing uncertainty and risk-as a central variable in the trust process. Even in promising research on "the role of trust in the transition to sustainable energy" [22], the capacity of rational choice and other fledgling trust concepts is overstretched in that "all are based on a common foundation: trust is a feeling or belief that someone (or some institution) will act in your best interest" ([22], p. 2615). Not only is the crucial element of suspension-the core of studying trust-missing in this definition; moreover, this definition limits the possible references of trust to micro-scale units such as "someone (or some institution)." In contrast, the approach presented in this paper relies on trust and confidence in abstract systems in a very specific manner $[55,56]$ that we will further unfold in the following sections.

While trust is already significant in many areas of the energy sector (e.g., investment decisions, market transactions, power plant and network operations), it will probably become even more important in future constellations, if the public's inclusion is required. The transformation of an ES cannot happen thus unless all actors modify their attitudes (or adopt new ones) with respect to new technologies, regulatory frameworks, and market opportunities. Such a transformation of attitude cannot happen through personal relationships; instead, trust in abstract systems is required [56]. Everyone affected by the transformation of the ES is forced to evaluate if the changing system will perform as expected. The function of trust is to enable engaging in new forms of interaction, which the system will offer as arising opportunities. However, evaluation must happen prior to monitoring whether the desired outcomes materialize. Therefore, the problem of intransparency is not only characterized by the trust addressees' degrees of freedom or the possibility of technical failure. Foremost, we should consider the necessity to momentarily close the temporal gap to an open future by a "leap of faith" [26, 50]. Trust is the grease which softens the frictions of constant rational calculation on what can "go wrong."

Trust is intrinsically interwoven in the sustainment of present operations:

Trust can only be secured and maintained in the present. Neither the uncertain future nor even the past can arouse trust since that which has been does not eliminate the possibility of the future discovery of alternative antecedents. [...] The basis of all trust is the present as an unbroken continuum of changing events, as the totality of states in respect to which events can occur [21]
Analyses of system transformation hinge on the temporal horizon chosen; e.g., German scenarios of possible energy generation and consumption paths and respective addressees of trust vary according to whether they concern the next year, the next 5 years, or the next 30 years. Visions of potential smart grid components concern its final state, which is temporally located far away, at approximately 2050, according to the federal government [1]. Hence energy practitioners describe some envisioned components, such as virtual power plants, as "fantasies." The following section discusses visions of future ES, particularly the German ES Transformation ("Smart grids" section). Then, the concept of trust will be clarified further ("Familiarity, confidence, and trust in complex systems" section) and the reader will discover three pivotal trust challenges for smart grids ("Results: three case studies about smart grids-consumers, investors, and those affected" section).

\section{Smart grids}

The German ES Transformation is largely a development toward a smart grid. Nearly every significant political party refers to smart grid development, while the government funds large-scale testing with smart grid components, such as "E-Energy" [2], and promotes the development of an "Internet of Energy" [57]. Although a smart grid (understood as a mere effectuation of energy consumption) is conceivable without a large integration of renewable energy sources (RES), the German ES Transformation relies on innovations in this area to mitigate ensuing volatilities.

The smart grid cannot function successfully without "appropriate" smart meter usage and economic activity, as determined in prevalent visions. Hence, the success of the smart grid is very dependent on the behavioral conformity of prosumers, because actions (trust), the absence of actions (lack of trust), and counteractions (distrust) of individual smart meter users and small-scale electricity vendors in emerging energy markets may have significant cumulative effects on the overall rationality-and therefore success-of the ES. We assess the relevance of trust as a social mechanism in terms of its impact as an actionenabling mechanism for electricity consumers confronted with unfamiliar complexity and facing unprecedented decision-making and reflexivity in smart grids [58]. We emphasize the consequences of trust in the sense that a given action (smart meter usage, economic activity) actually will occur, or remain absent, because of a lack of trust.

These expectations imply a qualitative change in the underlying prerogatives of the energy sector. An active trust in technology (smart meters), markets (reputation management, sanction systems), and organizations (supervision, trust intermediaries) will become indispensable for the prospective ES to work, given the critical role of decentralized consumption and feed-in units for system performance. Mere acceptance of infrastructure plays a smaller role. 
Hence, the German ES is moving toward a smart grid model based upon large-scale consumer involvement ${ }^{8}$ (c.f. how four out of five smart grid components affect the average electricity customer (Table 2)). Since this transformation will probably be most significant for the average, private consumers, this paper focuses primarily on their broad household usage.

\section{Familiarity, confidence, and trust in complex systems}

Even though past ES were technically complicated [39], electricity consumption was quite simple and rarely led, in the OECD world, to users' disappointment in the reliability of an ES. In Germany, which possesses a particularly reliable power grid, an uninterrupted electricity supply is expected, and consumers have built a high degree of familiarity in interacting with electricity services. Familiarity indicates a low level of risk reflection on technology interaction ${ }^{9}$ and a high level of confidence, thus resulting in a very routine mode of interaction. When consumers' positive experiences with technological services are constantly reaffirmed, familiarity and stable expectations are built, which can eventually obscure huge technological infrastructure systems in an unnoticeable latency [28]. Although confidence is related to trust, it is not bound to decision-making, because disappointments in confidence are attributed to external factors rather than to one's own decisions [55].

Like trust, distrust is an action-enabling strategy. Distrust is not the opposite of trust, but its functional equivalent. Distrust reduces complexity into a narrow action corridor by making a few actions probable and certain others highly unlikely [21]. Distrust provokes counterstrategies by consumers who wish to circumvent the distrusted situation or object, thus aspiring autonomy, searching for alternatives and perhaps even boycotting. Unlike a lack of trust, which can hinder action, distrust results in a mobilization of action potential.

In the past, consumers could afford to distrust both the regime operating the ES and its technology (e.g., nuclear plants) without causing an overarching, systemic consequence. ${ }^{10}$ Since smart grids depend on the behavior of single users, they are more vulnerable to cumulated effects of massive simultaneous action-and such action can fall outside the expected behavioral patterns. As large technical systems become interactive technical systems with direct consumer involvement through ICT and market participation, the systems' invisibility will dissolve. Smart grids will

Table 2 Five components of smart grids [7]

\begin{tabular}{llll}
\hline Domains of smart energy technology & & \\
\hline DSM Virtual power & Electric vehicle & Energy & Self-healing \\
plants & management & prosumers & networks \\
\hline
\end{tabular}

From left to right: ICT, increasing connectivity/communication, (distributive) grid extension, decentralization, implementation of "artificial intelligence" contain far more "access points," i.e., intersections (smart meters, market organizations, electric vehicles) where consumers can do "facework" [56] with the impersonal ES. This increases the system's complexity and the potential for uncertainty and incalculable consumer action, reinforcing the system's foundation on trust instead of control.

In the German ES Transformation, complexity is an issue in its own right, depicted by experts as the central challenge which they face. Our interviewees explicitly stated that the complexity has a direct bearing on their work. They claimed that a high proportion of non-knowledge exists and pointed out the fragility of interdisciplinary knowledge between engineering (energy technology), computer science (grid communication), and social science (consumer behavior). They portrayed the German ES Transformation as a large real-time experiment rather than a planned project-an appraisal which substantiates the impact of complexity.

\section{Results: three case studies about smart grids-consumers, investors, and those affected}

As trust reduces complexity and thus enables action under future uncertainty, trust unfolds its vital effect in the face of non-knowledge and becomes manifest in the risk-taking act [59]. We shall illustrate, with case studies about smart grid actors, the growing need for distrust, and trust as a "certainty equivalent" [21], to manage rising degrees of contingency, uncertainty, and risk, particularly from a consumer perspective.

\section{Consumers}

Electricity has been available to consumers as a quasiinvisible force [58] and, for decades, as an unquestioned resource [60]. The currently passive consumption will increasingly become a matter of liability and daily attention, as the organization of generation, transport, and distribution of electricity is transformed. For the integration of volatile RES, "smart technology" is envisioned to help align consummation during phases of low or high RES output. Proponents of "smart meters" claim that customers can be encouraged to save energy (because smart meters offer transparency about quantity and costs), while operators can monitor and control appliances of customers (because smart meters provide data, identity, and location of home appliances), and control their maximum load demand during peak load (because supply can be disconnected via smart meter if customers exceed their quotas) [61]. According to the technical premises of dominating visions, "smart technology" not only results in more efficient use of energy, it will also provide "grid-supportive" measures and thereby help maintain grid stability and security of supply [2, 62].

In sharp contrast to the traditional supply-driven consumption, smart grids require consumers who actively 
adapt their consumption behavior through smart meters allowing for DSM, new tariff systems, mobile applications, etc. Consumers may decide to use electrical appliances (e.g., heat pumps, air-conditioning, and washing machines) and discharge vehicle batteries to the grid only at determined times, responding to signals securing the demandsupply equilibrium $[2,7,63]$.

As choice always involves uncertainty, consumers' decisions expose the system to trust and distrust vulnerabilities. A basic choice consists in whether to comply with the expectations of engineers, operators, and/or supervisors. Consumers may reject the effort of rational calculation: They may not gain familiarity and fail to gather information by comparing possibilities and prices; they may reject the delegation of control to machines, operators, and supervisors. Yet delegating one's power to make decisions, even partially (e.g., to software agents in smart meter appliances), is itself a decision.

With a view to encouraging consumers' compliance, psychologists research the regulation of incentives (e.g., online platforms, price signaling, and smart meter setup). In many European countries [3], including Germany (E-Energy projects [2]), large-scale regulatory experiments are carried out. The fact that incentives are heavily researched is a strong indicator for the social instability caused by the freedom of choice which consumers are likely to have. Therefore, incentive mechanisms also create risk. Incentives can fail and lead collective consumer behavior into unanticipated directions. If consumer behavior becomes a critical factor for system operation, then the risk of cumulated effects (like collective distrust against the new grid or parts of it) will rise. During the initial phases of transition in the Netherlands and California (USA), distrust was manifested by protest against the installation of smart meters $[4,12] .^{11}$

In 2011, the US Government Accountability Office [64] concluded in its report on Electricity Grid Modernization that "consumers are not adequately informed about the benefits, costs, and risks associated with smart grid systems." As smart grids enable the transmission of large amounts of data about household activity, fear rises about privacy and customer security with regard to the unauthorized use or modification of sensitive "personal data" (that is, recorded data attributed to a person, e.g., name, contact, biographical data like individual preferences, transaction history, or recorded activities), or of information derived from such data (including the compilation of individual profiles or scores) [10]. Some experts anticipate "nothing short of a paradigm shift in industry from the current hardware centric focus on system adequacy and reliability, towards the inclusion [of] a more directly consumer-oriented view of security" [11]. However, even if governments attempt to enforce the implementation of security standards and the industry promises to incorporate these standards, the problem of "authenticity" arises as soon as trust is lacking and the attribution of motives is prevalent. The EU commission has mandated the European Standardization Organization (ESO) to develop security standards for smart meters. Commercial interests dominate, since the ESO relies on the expertise of commercial parties. Hoenkamp and Huitema claim that "These [standards] will be useless if the public rejects them" ([12], p. 5).

The public's fears could sabotage the envisaged overall rationality of the system. Comparable "emergent effects" of cumulative, collective behavior have been observed in other sectors, such as the rejection of E10 biofuel in Germany, ${ }^{12}$ sudden investment withdrawals in the financial sector [65], and periodic, or even constant, distrust in the food sector, as with Enterohaemorrhagic Escherichia Coli bacteria (EHEC) in Europe [66] or milk powder in China. ${ }^{13}$

\section{Investors}

As mentioned above, smart grid visions encompass numerous actors engaged in the energy trade. In some countries and regions, this process is well under way; particularly, small and decentralized RES units with self-generated electricity are increasing in Germany, Denmark, or California (USA). It is expected that electricity loads will serve selfsupply and assist with grid stability and, moreover, cause new markets to flourish, so that every actor equipped with technology for photovoltaics, wind, combined heat and power, or geothermal applications, etc., can act as an electricity vendor for "virtual power plants" and "smart markets" ([2, 7], e.g., [63, 67]).

The desired "prosumers" are expected to consume and produce electricity simultaneously, making them both consumers and entrepreneurs. Even at present, such developments and prospects are significant, as can be illustrated by Siemens research: The company created a web portal, with concomitant mobile applications, to explore the potential of virtual power plants in Germany and in European cross-border conglomerates [68]. Its main objective was to form stronger power plants that every participant could benefit from. Therefore, Siemens set up cloud computing networks between local providers and various electricity generators who were willing to combine their electricity loads with those of the other actors. The means to achieve this were "virtual," the actors being "plugged" together through exposition of available load information (kWh, gigawatt) in the cloud. In this way, virtual power plants emerge through ICT as a fresh new field of energy commerce.

Like the global financial system [65], the ES may see the establishment of rating agencies as "guardians of trust" which become crucial to the formation of market networks. According to smart grid visions, institutions 
which provide recommendations can increase the probability of market interaction, by generating a reputation or signaling certain qualities $[2,7,69]$. They can be certification agencies, market intermediaries, or online platforms.

Since the smart grids' implementation depends, at least partly, on consumers' attitudes, we need to determine the qualities of these attitudes more precisely. We can determine these attitudes by using the analytic distinction between trust and confidence: An actor must, for example, explicitly trust in the price stability of her chosen supplier's electricity, whereas she must implicitly feel confident about the stability of general market operation, in how responsibilities are allocated, how security of supply is maintained, and how legal security is guaranteed in the emerging business world.

For active prosumers to be endowed with actionability in this diffuse new system, trustful decision-making can only be embedded in a climate of general confidence in (the parts of) the overall system. This interdependence between confidence and trust can be pictured as a relation of mutual spirals, where, progressively, one either reinforces the other (virtuous circle), or one weakens the other (vicious circle). Together, confidence and trust determine the future state of the system [55]. In a virtuous circle, confidence and trust mutually stabilize each other, creating an atmosphere of business optimism and leading to a massive exploitation of opportunities in technology and markets.

The scenario of a vicious circle is particularly relevant during the mid-term phase of the German ES Transformation. Investment in RES (which may be provided by small private investors like average consumers, but also by local providers and larger industries) is crucial for smart grids to evolve. Business representatives and scientific experts insist that confidence in a stable legal framework and financial returns for the investments in RES in the coming years are necessary. However, some actors doubt whether these investments are being made, because uncertainty in the business seems quite acute (according to an interviewed expert from a business association). Certain actors' distrust extends to skepticism of the system's ability to maintain security of supply; some electricity-intensive companies have even begun building their own power plants (according to an interviewed expert from academia).

A lack of trust among consumers and investors is not necessarily a negative development, nor does our discussion intend to promote some sort of "trust creation" for smart grid implementation. It may well be that involved actors are right to distrust-time will show. We merely wish to point out that the expectations of a majority of smart grid practitioners, promoters, and stakeholders do not take into sufficient account the functions and consequences fulfilled by trust, lack of trust, and distrust (e.g., [1, 3]). Indeed, distrust can serve an important function of learning and being conscious and critical of relevant changes in technology or policies. Notably, distrust can counter an excessive accrual of trust, after the equilibrium of trust and distrust has tipped toward the trust side, adding up to "blind trust" (which in everyday life we may call "carelessness").

\section{Those affected}

In the foreground of the debate on transforming ES into smart grids and thereby integrating RES are appeals to consider the "public acceptance of emerging energy technologies" [9]. These technologies include smart grid facilities, grid extensions, and economic or legal measures that can accompany these technological changes. Most debates about public acceptance are centered on such infrastructure issues. Whenever a grid extension is planned, certain actors must decide on its localization. These siting choices are often accompanied by protest and/or resistance movements ("not in my backyard" problems). ${ }^{14}$ In Germany, such NIMBY problems are often dealt with politically, by application of legal (participatory or planning) procedures. When someone is exposed to phenomena such as grid extension or power plant sites near their residential area, they are affected by decisions taken elsewhere with little or no own decision-making involved, and thus, they slip into the role of a "personally affected party" in a technology conflict [70].

In Germany, the public debate about siting decisions, NIMBY problems, and, more generally, contentious technologies has a long-standing history which has encouraged actors and observers (politicians, scientists, business persons, civil associations, and non-profit organizations) to declare "acceptance" the social cornerstone of the German ES Transformation. ${ }^{15}$

Indeed, acceptance of infrastructures is crucial, as two projects in Germany exemplify: First, the SuedLink project is supposed to transport electricity from offshore wind parks on the northern German coast toward southern industrial recipients. Planning considers technical and economic criteria, as well as objections from those affected by the project; several participatory exercises have been implemented. Although initial propositions of the possible route tried to exclude cities, towns, hospitals, industrial sites, nature reserves etc., more than 3000 objections have so far been articulated and publicly discussed. ${ }^{16}$ Also, planning is influenced by several elections in the affected states or municipalities. Political parties openly demand postponement of the project because it interferes with local electoral campaigns and engenders strong opposition. ${ }^{17}$ Second is the South-East Direct Current Passage project: it concerns transmission lines from eastern to southern Germany. The government claims that energy generated from RES will be transported; however, at least a significant 
part of the public does not believe these claims, accusing the government and the responsible business companies of intending to build a route for the transportation of coal electricity, since the route is planned to begin in SaxonyAnhalt-a brown coal mining area. As protesters remain outraged about the proposed route to the southern region of Bavaria, the project had to be put on hold. ${ }^{18}$

These siting decisions are static and singular: "Static" indicates an asymmetry in the relationship between the affected actors and the technology or procedure, for, unlike the actors, neither the technology nor the procedure reacts to communication. "Singular" emphasizes the one-sided character of the decisions: Either one accepts, or one refuses, the infrastructure-there is no middle ground. Ordinary spheres of social interaction in the smart grid, though, require more active participation than "merely" being affected as outlined above; they require constant decision-making and decisions are facilitated by using trust as a social mechanism to reduce complexity. Even in the extraordinary situation where interaction concerns infrastructure, and where acceptance (understood as civil tolerance of infrastructure by absence of protest) is the preponderant form of social coordination, trust still plays an important role.

The relation between the concepts of trust and acceptance has not been clarified sufficiently by the social sciences. Yet with reference to Kohring [71], one could identify the very foundation of technology acceptance in strategies of attributing trust. With regard to the case of the German ES Transformation, one can draw two conclusions on the interplay of trust and acceptance: Firstly, as acceptance allows actors to primarily accept shared rules on (legal) proceedings in the place of shared outcomes [72], trust is the mechanism which compensates for this lack of factual knowledge. Since attending actual decision-making processes is reserved to elected politicians, trusting that a decision was taken based on solid reasoning and a competent assessment of the future is simplified by accepting that the decision to accomplish the German ES Transformation has been reached through a politically legitimate procedure. The fact of not-knowing the exact manner in which the decision has been reached is bridged by trust, provided one "accepts" the set of rules according to which the decision has been negotiated. In this way, siting decisions and NIMBY problems, as primary examples of acceptance conflicts, are always accompanied by trust in legal (decision-making, participatory, and planning) procedures.

Moreover, a functional shift of acceptance in the German ES Transformation case can be expected: In earlier periods of ES development, acceptance issues limited to particular region proceedings (e.g., in a certain federal state) were a cause in their own right. Today, the German ES Transformation is observed by the entire nation, and the public's observation of regional acceptance can serve as an indicator of system trust building. To be more precise, the degree of confidence can be associated with a public observation of (successful or failing) acceptance creation in regions where grid extensions actually take place and must be dealt with by personally affected fellow citizens.

From a temporal perspective, these developments indicate that (i) processes of being affected and investing trust in procedures mainly occur during current grid extension projects; (ii) from a mid-term perspective, these processes occur along the transformation period; and (iii) in the smart grid of the far future, the significance of genuine acceptance phenomena concerning physical infrastructures is likely to vanish.

\section{Discussion: an "architecture of trust" for ES}

Over time, consumers, investors, and other stakeholders' attitudes toward the ES have coalesced into expectations which are-and will continue to be-challenged. These expectations are meanwhile inherent to the structures and institutions of the ES; it shapes their manifestation, impact, and degrees of stability and change. The extent and manner in which elements of a system can relate to each other are built into structures, and, therefore, structures determine (in technical systems), or condition (in social systems), the processes of each system. When we encounter structures, we can develop expectations of what will happen in the future. Moreover, after a longer period, we increasingly experience familiarity upon acting with, or within, structures.

Based on this sense of familiarity, structures support an architecture of trust [73] within which actors can identify persons or objects to whom or which they can address their expectations with respect to the ES (addressees). The public can identify certain institutions as representatives of "the energy system," e.g., energy providers (who maintain price stability), public agencies for technical supervision (who ensure security of supply), and sanction agencies (who enforce regulations) [56]. As addressees, these institutions represent mutually shared expectations to which services and outputs are attributed [82], either when reassurances about fulfillment of expectations are necessary (e.g., "electricity supply is safe") or when disappointments occur, be they singular or continuous (e.g., "the engineers will manage/not manage the transition"). Notwithstanding actors' familiarity with structures and institutions of the ES, their expectations are challenged at every moment in which they deal with the system and its perceived representatives. Their expectations are continuously confirmed, negated, or modified in concrete situations during the operation of the ES. It is this type of sustainment-driven by trust, distrust, and confidence-that 
will crucially determine the potentials of sustainability in the future system.

For consumers, this means a redirection of familiarity toward either actively trusting and running the risk of being overconfident or creating collective distrust. Either investors trust and therefore invest in fledgling smart grid technology, thus contributing to an investment climate, or investors lack the confidence to support the ES, given the instability of legal frameworks. Finally, those personally affected by spatial planning issues have to accept local decision-making while, more importantly, investing trust in planning procedures. For the success of the ES on a national level, the local settlement of NIMBY conflicts is an essential means of building system trust. Meanwhile, as our case studies demonstrate, distrust by citizens in the form of protest, investment holdbacks, or technology refusal may even provide learning opportunities. Since every act of trust holds a risk [21, 73] and since the German ES suffers many flaws, setbacks, and risks during the transformation, choosing to balance trust and distrust may be the better option on the road toward sustainability.

From a functional perspective, it is inevitable that we attribute trust, in order to reduce complexity, to make selections, and to build up actionability, for no one can distrust everything simultaneously. The framework of a trust architecture highlights prominent trustees in the social environment, so that selections are limited to certain potential addressees. This leads to various reconfigurations of trust and distrust, action and counteraction, affirmation, negation, apathy, etc. According to Luhmann [47], one can direct expectations at persons (e.g., opinion leaders), roles (e.g., engineers), programs (e.g., energy transformation policy), and values (e.g., data privacy, sustainability). Within the framework for the ES evolution, these addressees of trust and distrust will determine the success and failure of smart grids. At this point, we cannot present methods for managing the systemic consequences of trust, distrust, and confidence; we have to settle for demonstrating their status as solutions to socio-technical problems of ES transformation.

\section{Conclusion}

Concepts of trust, distrust, and confidence offer valuable insights into the relations of various actors of the sociotechnical ES. With these insights, we can challenge some assumptions of technological visions. Technical innovation and institutional change cannot, alone, guarantee active participation by the public. Given that familiar structures and institutions of the ES are changing, we need to ascertain a future architecture of trust which offers all participants certain addressees for their attribution of trust. The authors aim at conducting further empirical research to investigate processes of trust and distrust attribution.

\section{Endnotes}

${ }^{1}$ The debate concerns not only the provision of electricity but also broader infrastructures, including technologies for heating and cooling and technologies using various energy sources such as gas. However, in the following, we concentrate on the transformation of the electricity domain, because not only do we find the most drastic changes in this area but also many innovations of exploiting various energy carriers align to the electricity system, like geothermal electricity.

${ }^{2}$ Research on the expectations about new smart technologies is sometimes misleading [74]; similarly, rationally calculating cost and benefits is also prone to lead to mistakes.

${ }^{3}$ Discussions about "empowerment" also point in the direction of the capacity to act $[75,76]$.

${ }^{4}$ In Germany, such "associations" are often comparable to American non-profit organizations.

${ }^{5}$ Likewise, Ashby [77] characterizes machines as "law-abiding," because no machine can be called "self-organizing," as it cannot automatically change its way of organization.

${ }^{6}$ Normal Accident Theory shows how non-linear operations in tightly coupled structures inevitably lead to failures and accidents and therefore to negative surprises [78].

${ }^{7}$ Data from our interview with a representative of a German energy business association.

${ }^{8}$ This assumption was strongly corroborated at a smart grid congress in Karlsruhe, Germany, in 2014, where a central message was "the client as [a] central future asset" [79].

${ }^{9}$ Examples of low-risk reflection include interaction with cell phones, public transport, and cars.

${ }^{10}$ The consequences of a "crisis of trust" can be more severe for the actionability of specific organizations than for consumers: "For some [organizations], the crisis of trust is especially acute, coloring and constraining virtually all their actions and choices" [80].

${ }^{11}$ See, for example, Felicity Barringer: "New Electricity Meters Stir Fears." The New York Times, 30.01.2011, or initiatives like www.stopsmartmeters.org.

${ }^{12}$ See Hughes D' Arcy: "Biofuel scepticism prompts German summit." The Guardian, Accessed 07.03.2011.

${ }^{13}$ See Qiang Zhang: "Distrust of Chinese milk persists despite Fonterra case." BBC News China, 13.08.2015 (http://www.bbc.co.uk/news/world-asia-china-23582282; accessed 16.02.2015).

${ }^{14}$ Siting relates to processes surrounding decision-making about the regional and local spaces and corridors to be used for infrastructure installations. NIMBY opposition can be a reaction to it.

${ }^{15}$ See $[1,2,57,81]$. 
${ }^{16}$ See "Dokumentation des Dialogprozesses vor der Antragsstellung." TenneT TSO GmbH (http://suedlink. tennet.eu/bundesfachplanung/antrag-6/dialogprozess.html; accessed 05.02.2015).

${ }^{17}$ See Nicolai Kwasniewski: "Gleichstromtrasse Suedlink: Planung und Verlauf der Stromautobahn." Spiegel Online, 05.02.2014.

${ }^{18}$ See Markus Szymanski, Mike Balser, and Marlene Weiß: "Der Stress mit den Stromtrassen"; sueddeutsche.de, 30.07.2014.

\section{Competing interests}

This work is the result of research conducted within the Helmholtz Initiative ENERGY-TRANS (www.energy-trans.de/english/index.php). The authors declare that they have no competing interests.

\section{Authors' contributions}

The article was jointly prepared by both authors. Both authors read and approved the final manuscript.

\section{Authors' information}

Christian Büscher is a senior researcher at the Institute of Technology Assessment and Systems Analysis (ITAS) at Karlsruhe Institute of Technology (KIT). He holds a Doctoral Degree in Sociology (Dr. Phil.) from Darmstadt Technical University and a diploma in Sociology (Diplom-Soziologe) from the University of Bielefeld. His research interests are in the area of technology assessment and risk and environmental sociology. His list of publications includes papers in peer-reviewed journals and in edited books.

Patrick Sumpf is a research associate at the Institute of Technology Assessment and Systems Analysis (ITAS) at Karlsruhe Institute of Technology (KIT). He holds a B.A. in Political Science and an M.A. in Political Communication, both from Bielefeld University, Germany. He currently is a doctoral candidate at Mannheim University, Germany. His work focuses on trust research.

\section{Acknowledgements}

The authors wish to thank the editors of this journal for their useful suggestions Discussion with colleagues from the ENERGY-TRANS project helped us clarify arguments. We are especially grateful for the revisions by Mira Klemm.

\section{Received: 7 May 2015 Accepted: 12 November 2015}

\section{Published online: 01 December 2015}

\section{References}

1. BMWi/BMU (2011) The Federal Government's energy concept of 2010 and the transformation of the energy system of 2011. Berlin

2. B.A.U.M. Consult (2012) Smart Energy made in Germany. Interim results of the E-Energy pilot projects towards the Internet of Energy. Munich/Berlin

3. Giordano V, Gangale F, Fulli G, Jiménez MS (2011) Smart Grid projects in Europe. JRC Reference Reports by the Joint Research Centre of the European Commission

4. AlAbdulkarim L, Lukszo Z, Fens T (2012) Acceptance of privacy-sensitive technologies: Smart Metering Case in the Netherlands. Third International Engineering Systems Symposium (CESUN), Delft University of Technology, Delft

5. Amin M (2001) Toward self-healing energy infrastructure systems. IEEE Comput Appl Power 14:20-28. doi:10.1109/67.893351

6. Ma Y, Zhou L, Tse N, Osman A, Lai LL (2009) An initial study on computational intelligence for smart grid. In: Proceedings of the 2009 International Conference on Machine Learning and Cybernetics., pp 3425-3429

7. Ramchurn S, Vytelingum P, Rogers A, Jennings N (2012) Putting the "smarts" into the smart grid: a grand challenge for artificial intelligence. Commun ACM 55:86-97

8. Wissner M (2011) The smart grid-a saucerful of secrets? Appl Energy 88: 2509-2518

9. Kasperson RE, Ram BJ (2013) The public acceptance of new energy technologies. Daedalus 142:90-96
10. Cavoukian A, Polonetsky J, Wolf C (2010) SmartPrivacy for the smart grid: embedding privacy into the design of electricity conservation. Identity Inf Soc 3:275-294. doi:10.1007/s12394-010-0046-y

11. Pearson ILG (2011) Smart grid cyber security for Europe. Energy Policy 39: 5211-5218. doi:10.1016/j.enpol.2011.05.043

12. Hoenkamp RA, Huitema GB (2012) Good standards for smart meters. In: European Energy Market (EEM), 2012 9th International Conference on the European Energy Market.10.1109/EEM.2012.6254820

13. Wüstenhagen R, Wolsink M, Bürer MJ (2007) Social acceptance of renewable energy innovation: an introduction to the concept. Energy Policy 35:2683-2691. doi:10.1016/j.enpol.2006.12.001

14. Wolsink M (2012) The research agenda on social acceptance of distributed generation in smart grids: renewable as common pool resources. Renewable Sustainable Energy Rev 16:822-835. doi:10.1016/j.rser.2011.09.006

15. Musall FD, Kuik O (2011) Local acceptance of renewable energy - a case study from southeast Germany. Energy Policy 39:3252-3260. doi:10.1016/j. enpol.2011.03.017

16. Ciupuliga AR, Cuppen E (2013) The role of dialogue in fostering acceptance of transmission lines: the case of a France-Spain interconnection project. Energy Policy 60:224-233. doi:10.1016/j.enpol.2013.05.028

17. Zoellner J, Schweizer-Ries P, Wemheuer C (2008) Public acceptance of renewable energies: results from case studies in Germany. Energy Policy 36: 4136-4141. doi:10.1016/j.enpol.2008.06.026

18. Künneke R, Mehos DC, Hillerbrand R, Hemmes K (2015) Understanding values embedded in offshore wind energy systems: toward a purposeful institutional and technological design. Environ Sci Policy 53:118-129. doi:10.1016/j.envsci.2015.06.013

19. acatech (2011) Akzeptanz von Technik und Infrastrukturen. Anmerkungen zu einem aktuellen gesellschaftlichem Problem. Deutsche Akademie der Technikwissenschaften acatech, München

20. Ribeiro PF, Polinder H, Verkerk MJ (2012) Planning and designing smart grids: philosophical considerations. IEEE Technol Soc Mag 31:34-43. doi:10.1109/MTS.2012.2211771

21. Luhmann N (1979) Trust and power. Wiley, Chichester

22. Bellaby P, Eames M, Flynn R (2010) The role of "trust" in the transition to sustainable energy. Energy Policy 38:2613-2614. doi:10.1016/j.enpol.2009. 03.066

23. Knudsen M (2010) Surprised by method — functional method and systems theory. Forum Qualitative Sozialforschung/ Forum: Qualitative Social Research 11

24. Kohring M (2004) Vertrauen in Journalismus: Theorie und Empirie. UVK-Verl.-Ges, Konstanz

25. Strulik T (2004) Nichtwissen und Vertrauen in der Wissensökonomie. CampusVerl, Frankfurt [u.a.]

26. Möllering G (2006) Trust: reason, routine, reflexivity, 1st edn. Elsevier, Amsterdam [u.a.]

27. Strulik T (2006) Rating agencies, ignorance and the knowledge-based production of system trust. In: Strulik T, Willke H (eds) Towards a Cognitive Mode in Global Finance. The Governance of a Knowledge-based Financial System. Campus, Frankfurt am Main, New York, pp 239-255

28. Edwards PN (2004) Infrastructure and modernity: force, time, and social organization in the history of socio-technical systems. In: Misa T, Brey P, Feenberg A (eds) Modernity and Technology. MIT Press, Cambridge, London, pp 185-225

29. Hughes TP (1983) Networks of Power: Electrification in Western Society: Baltimore 1880-1930. The Johns Hopkins University Press, Baltimore

30. Hughes TP (1987) The evolution of large technological systems. In: Bijker WE, Hughes TP, Pinch TJ (eds) The Social construction of technological systems: new directions in the sociology and history of technology. MIT Press, London. pp 51-82

31. Mayntz R (1993) Grosse technische Systeme und ihre gesellschaftstheoretische Bedeutung. Kölner Zeitschrift für Soziologie und Sozialpsychologie 45:97-108

32. Mayntz R (2009) The changing governance of large technical infrastructure systems. In: Über Governance. Institutionen und Prozesse politischer Regelung. Campus, Frankfurt am Main, New York, pp 121-150

33. Edwards PN, Jackson SJ, Bowker GC, Knobel CP (2007) Understanding infrastructure: dynamics, tensions, and design. DeepBlue, Ann Arbor

34. Jackson SJ, Edwards PN, Bowker GC, Knobel CP (2007) Understanding infrastructure: history, heuristics and cyberinfrastructure policy. First Monday 12

35. Geels FW (2004) From sectoral systems of innovation to socio-technical systems: insights about dynamics and change from sociology and institutional theory. Res Policy 33:897-920 
36. Smith A, Stirling A, Berkhout F (2005) The governance of sustainable socio-technical transitions. Res Policy 34:1491-1510. doi:10.1016/j.respol. 2005.07.005

37. Künneke RW (2008) Institutional reform and technological practice: the case of electricity. Ind Corporate Change 17:233-265

38. La Porte TR (1975) Organized social complexity: explication of a concept. In: Organized social complexity: challenge to politics and policy. Princeton Univ. Press, Princeton, pp 3-39

39. Kröger W, Zio E (2011) Vulnerable systems. Springer, London, Dordrecht, Heidelberg, New York

40. Gross M, Mautz R (2015) Renewable energies. Routledge, London, New York

41. Carlsson B, Stankiewicz R (1991) On the nature, function and composition of technological systems. J Evol Econ 1:93-118. doi:10.1007/BF01224915

42. Fuenfschilling L, Truffer B (2014) The structuration of socio-technical regimes-conceptual foundations from institutional theory. Res Policy. doi: 10.1016/j.respol.2013.10.010

43. Strunz S (2014) The German energy transition as a regime shift. Ecol Econ 100:150-158. doi:10.1016/j.ecolecon.2014.01.019

44. Luhmann N (2005) Risk-a sociological theory. Aldine Transactions, New Brunswick (USA), London (UK)

45. von Foerster H (1993) KybernEthik. Merve, Berlin

46. Elster J (1979) Ulysses and the Sirens. Studies in rationality and irrationality. Cambridge University Press, Cambridge

47. Luhmann N (1995) Social systems. Stanford University Press, Stanford

48. Khan SR (2014) "Humans cannot communicate" - unravelling the mental knots of Niklas Luhmann. Contemp Sociology 43:49-55. doi:10.1177/ 0094306113514538 a

49. Luhmann N (2012) Theory of society_volume 1. Stanford University Press, Stanford

50. Simmel G (1978) The philosophy of money. Routledge \& Kegan Paul, Boston

51. Möllering G (2001) The nature of trust: from Georg Simmel to a theory of expectation, interpretation and suspension. Sociology 35:403-420. doi:10. $1177 / 50038038501000190$

52. Möllering G (2013) Process views of trusting and crises. In: Bachmann R, Zaheer A (eds) Handbook of Advances in Trust Research. Edward Elgar, Cheltenham, pp 285-305

53. Lewis JD, Weigert AJ (2012) The social dynamics of trust: theoretical and empirical research, 1985-2012. Social Forces 91:25-31. doi:10.1093/sf/sos116

54. Möllering G (2006) Trust, institutions, agency: towards a neoinstitutional theory of trust. In: Bachmann R, Zaheer A (eds) Handbook of Trust Research. Edward Elgar, Cheltenham, pp 355-376

55. Luhmann N (1988) Familiarity, confidence, trust: problems and alternatives. In: Gambetta D (ed) Trust. Making and Breaking Cooperative Relations. Basil Blackwell, Oxford [u.a.], pp 94-107

56. Giddens A (1990) The consequences of modernity. Polity Press, Cambridge

57. Appelrath HJ, Kagermann H, Mayer C (2012) Future energy grid: Migrationspfade ins Internet der Energie. acatech, Cambridge

58. Shove E, Warde A (1998) Inconspicuous consumption: the sociology of consumption and the environment. www.lancaster.ac.uk/fass/resources/ sociology-online-papers/papers/shove-warde-inconspicuous-consumption. pdf, retrieved 16.09.2015

59. Skinner D, Dietz G, Weibel A (2013) The dark side of trust: when trust becomes a "Poisoned Chalice". Organization. doi:10.1177/1350508412473866

60. Fekete A (2011) Common criteria for the assessment of critical infrastructures. Int J Disaster Risk Sci 2:15-24. doi:10.1007/s13753-011-0002-y

61. Depuru SSSR, Wang L, Devabhaktuni V (2011) Smart meters for power grid challenges, issues, advantages and status. Renewable Sustainable Energy Rev 15:2736-2742

62. Amin SM, Wollenberg BF (2005) Toward a smart grid. IEEE Power Energy Magazine 3:34-41.

63. Amin SM, Giacomoni AM (2011) Smart grid-safe, secure, self-healing. IEEE Power Energy Magazine 10:33-40. doi:10.1109/MPE.2011.943112

64. GAO (2011) Electricity grid modernization: progress being made on cybersecurity guidelines, but key challenges remain to be addressed. U.S Government Accountability Office, Washington, D.C

65. Shapiro SP (1987) The social control of impersonal trust. Am J Sociol 93:623-658

66. Sumpf P (2013) Mechanismen der Vertrauens(de)konstitution in Öffentlichen Krisen - Das Beispiel EHEC O104:H4. In: Medien müssen draußen bleiben! Wo liegen die Grenzen politischer Transparenz? Frank \& Timme, Berlin, pp 217-235
67. BNetzA (2011) "Smart grid" und "smart market". Eckpunktepapier der Bundesnetzagentur zu den Aspekten des sich ändernden Energieversorgungssystems. Bundesnetzagentur, Bonn

68. Jopp K (2014) Virtuelle Kraftwerke in der Cloud. Energy 20:23-25

69. Orwat C (2011) Systemic risks in the electric power infrastructure? TATuP 20:47-55

70. Luhmann N (1990) Technology, environment and social risk: a systems perspective. Organ Environ 4:223-231. doi:10.1177/108602669000400305

71. Kohring M (2001) Vertrauen in Medien - Vertrauen in Technologie. Akademie für Technikfolgenabschätzung, Baden-Württemberg

72. Vollmer H (1996) Akzeptanzbeschaffung: Verfahren und Verhandlungen. Zeitschrift für Soziologie 25:147-164

73. Strulik T (2011) Vertrauen. Ein Ferment gesellschaftlicher Risikoproduktion. Erwägen, Wissen, Ethik 22:239-251

74. Krishnamurti T, Schwartz D, Davis A, Fischhoff B, de Bruin W, Lave L, Wang J (2012) Preparing for smart grid technologies: a behavioral decision research approach to understanding consumer expectations about smart meters. Energy Policy 41:790-797. doi:10.1016/j.enpol.2011.11.047

75. Verbong GPJ, Beemsterboer S, Sengers F (2013) Smart grids or smart users? Involving users in developing a low carbon electricity economy. Energy Policy 52:117-125. doi:10.1016/j.enpol.2012.05.003

76. Geelen D, Reinders A, Keyson D (2013) Empowering the end-user in smart grids: recommendations for the design of products and services. Energy Policy 61:151-161. doi:10.1016/j.enpol.2013.05.107

77. Ashby WR (2004) Principles of the self-organizing system. E:CO 6:102-126

78. Perrow C (1984) Normal accidents. Living with high-risk technologies. Basic Books, New York

79. Khala N, Sumpf P, Büscher C (2014) "Wir sind das Smart Grid" - Zu einer aktuellen Debatte unter InformatikerInnen. Bericht vom 2. Kongress Energie + Informatik - Dezentrale Energie smart verknüpft. TATuP 23:118-121

80. LaPorte TR, Metlay DS (1996) Hazards and institutional trustworthiness. Public Administration Rev 56:341-347

81. VDE (2008) Smart Distribution 2020. Virtuelle Kraftwerke in Verteilungsnetzen. Technische, regulatorische und kommerzielle Rahmenbedingungen. Verband der Elektrotechnik Elektronik Informationstechnik e.V. (VDE), Frankfurt am Main, Cambridge

82. Malle BF (1999) How people explain behavior: a new theoretical framework. Pers Soc Psychol Rev 3:23-48. doi:10.1207/s15327957pspr0301_2

\section{Submit your manuscript to a SpringerOpen ${ }^{\odot}$ journal and benefit from:}

- Convenient online submission

Rigorous peer review

- Immediate publication on acceptance

- Open access: articles freely available online

- High visibility within the field

- Retaining the copyright to your article

Submit your next manuscript at $>$ springeropen.com 